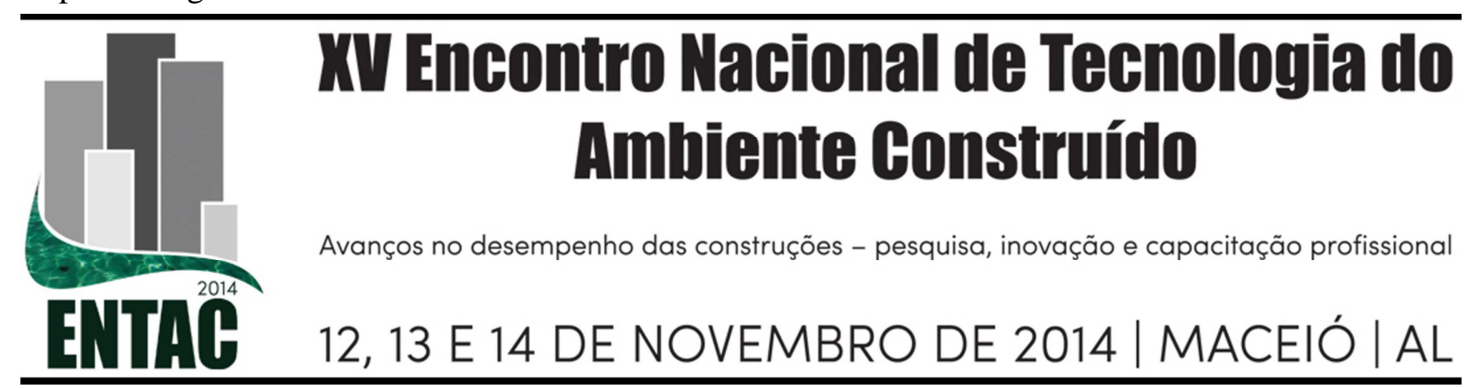

\title{
USO DE SISTEMAS DE ILUMINAÇÃO E VENTILAÇÃO: ESTUDO DE CASO DA ESCOLA DE ARQUITETURA DA UFMG
}

GONÇALVES, Camila Campos (1); SOUZA, Roberta Vieira Gonçalves (2)

(1) UFMG, e-mail: arq.camilacampos@gmail.com (2)UFMG, e-mail: robertavgs@gmail.com

\begin{abstract}
RESUMO
Após a década de 70, a eficiência energética tornou-se um tema muito discutido no Brasil e no mundo e originou diversas ações voltadas à conservação e eficiência. Apesar destes avanços, dados ressaltam que o potencial de economia energética dos edifícios não garante sua economia efetiva, em função de falhas de projetos e de como eles são utilizados. Esta pesquisa, parte de uma dissertação de mestrado, visa avaliar o comportamento de usuários quanto ao uso dos sistemas de iluminação, ventilação e controle da incidência solar. Utilizaram-se como estudo de caso salas de aula e laboratórios da Escola de Arquitetura da UFMG. O objetivo foi analisar, pelo método de Avaliação Pós-Ocupação, o uso destes sistemas e como as edificações e estes sistemas influenciam o comportamento dos usuários. Realizou-se um diagnóstico das salas para verificação das condições de iluminação natural, com o uso do Daysim e a avaliação das horas de insolação e levantamento dos sistemas de sombreamento existentes, levantamento do acionamento do sistema artificial e, para análise do comportamento dos usuários, foram feitas observações in loco, que avaliaram barreiras e potencialidades destes sistemas. As observações buscaram ainda verificar diferenças de comportamento entre grandes grupos de indivíduos, nas salas de aula, e pequenos grupos, nos laboratórios. Verificou-se que há hierarquia no uso dos sistemas nas salas de aula, sendo os professores os principais autores das alterações nestes. Os sistemas, em geral, não atendem às expectativas dos usuários que, em diversos momentos, têm dificuldades quanto ao seu uso. Eles tendem a atuar nos sistemas quando estão incomodados, portanto os ambientes mais eficientes são aqueles que menos exigem que os usuários atuem sobre eles. Desse modo, a principal contribuição deste trabalho foi identificar que o desempenho das edificações é consequência direta da maneira como elas são projetadas e entendidas por seus usuários.

Palavras-chave: comportamento dos usuários, eficiência energética, desempenho das edificações.
\end{abstract}

\begin{abstract}
After the 70s, energy efficiency has become a more discussed topic in Brazil and in the world, what originated several actions related to energy conservation and efficiency. Despite these advances, data highlights that the energy' saving potential of buildings does not guarantee its effective economy, as a consequence of projects' failure and of how buildings are used. This research, part of a master dissertation, aims to evaluate users' behavior on the activation of lighting, ventilation and control of solar incidence systems. UFMG Architecture School classrooms and laboratories were used as case study. The aim of this research was analyze, by the Post-Occupancy Evaluation method, the use of these systems and how these buildings and systems influence the behavior of users. We conducted a diagnosis of rooms for verification of natural lighting, using the Daysim and evaluation isolation hours and existing shading systems, artificial lift system and for analysis of user behavior, on-site observations, evaluating barriers and potentials of these systems were made. The observations were also used to verify the differences between large groups of individuals, in classrooms, and small groups, in laboratories. It was observed that there is a hierarchy in the systems use at classrooms, where teachers are the main authors of changes. In general, systems do not achieve users' expectations, who, at various times, have difficulties regarding to their use. The users tend to act in the systems when they are disturbed, so the most efficient environments are those who least require users to act on them. Thus, the main contribution of this work was to identify that the buildings' performance is consequence of their project and of the users' understanding.
\end{abstract}

Keywords: User behavior, Energy Efficiency, Buildings'performance. 


\section{INTRODUÇÃO}

As legislações surgidas após a década de 70 apontaram a importância da eficiência energética no mundo, no Brasil e especificamente nas edificações. O surgimento das certificações de edifícios e o esforço que tem sido observado atualmente em torno dessa questão apontam visíveis avanços na busca por edifícios mais eficientes. Todavia, o comportamento dos usuários, variável determinante para esta eficiência, ainda é pouco estudado, especialmente pelos teóricos brasileiros. Mais precisamente, sabe-se pouco sobre como funciona um ciclo de influências: de que maneira os usuários influenciam na eficiência energética e no conforto das edificações e de que maneira as edificações como estão propostas influenciam no comportamento dos usuários.

Ao analisarem o comportamento dos usuários quanto ao uso das janelas, Fritsch et al (1990), verificaram que a situação da janela (se aberta ou fechada) ao entrar em um ambiente vai influenciar em seu uso posterior. Se a janela está aberta, os usuários tendem a mantê-la aberta e se está fechada eles também tendem a mantê-la assim.

Lindelof e Morel (2006) classificaram os usuários em ativos e passivos, em função de sua disposição ou não em usar os controles disponíveis a eles. Os autores descreveram os resultados de uma análise feita na Suíça em que se verificou que, passado o período de chegada e saída dos usuários no escritório, o sistema de iluminação só era acionado novamente em casos de extremo desconforto. Além disso, raramente os funcionários utilizaram os dimerizadores disponíveis, acionando apenas os comandos ligar/desligar. Os autores concluíram que esse comportamento era consequência da posição dos interruptores, próximos à porta de entrada dos escritórios. Crisp (1978) verificou para um escritório no Reino Unido, em que todos os apagadores estavam localizados no mesmo interruptor, que o número de acendimentos das luminárias cujos apagadores estavam posicionados juntos e mais acima em relação aos demais foi maior, sem que houvesse nenhuma relação entre disponibilidade de luz natural ou ocupação da sala para que estas luminárias fossem acesas e não as demais. Reforçou-se, assim, a conclusão de que a posição dos controles tem relação direta com seu uso.

Reinhart e Voss (2003) ao desenvolverem uma pesquisa em um edifício de escritórios, nos quais trabalhavam uma ou duas pessoas, na Alemanha, concluíram que grupos de indivíduos possuem comportamentos parecidos, enquanto indivíduos isolados seguem padrões mais diversificados. Os autores verificaram ainda que todos os ocupantes do edifício consideraram a luz natural, o que poderia confirmar a influência da concepção arquitetônica e do sistema de iluminação proposto no prédio para o comportamento diferenciado dos seus usuários.

A ISO 50.001 (2011), baseada em um modelo de melhoria contínua - "Planejar- FazerVerificar-Agir" - também aponta que as instalações, equipamentos e sistemas possuem influência significativa no consumo de energia, não sendo apenas as pessoas as responsáveis por gastos desnecessários de energia. Norman (2010) reforça esta ideia ao condenar duramente a filosofia "culpe-e-treine" e afirmar que projetos ruins, criados para pessoas como gostaríamos que elas fossem e não como elas realmente são, são as verdadeiras causas da ineficiência dos projetos. Embora o papel do usuário na arquitetura tenha passado por uma evolução - de acessório a detentor de um papel mais efetivo - na prática, majoritariamente os usuários ainda são tratados como acessórios ou "usuários-tipo" diante da arquitetura. (LINO, VILLELA, FIGUEIREDO, 2009).

Hertzberger (2010) trata dos conceitos de "usuário" e "morador", fundamentais para o entendimento das diferenças de comportamento entre ocupantes de diferentes ambientes. De acordo com o autor, nos projetos arquitetônicos podem-se criar 
condições para um maior senso de responsabilidade e, consequentemente, um maior envolvimento no arranjo e inserção de mobiliários nos ambientes, de modo que o usuário/ocupante daquele espaço se transforme em um morador.

Por sua vez, Gyberg e Palm (2009) em estudo realizado em edificações residenciais, concluíram que para modificar o comportamento das pessoas deve-se garantir que as escolhas partam do individuo, com alternativas de projeto que não afetem o seu estilo de vida. Desse modo, a concepção do projeto arquitetônico, com propostas que garantam melhor conforto e eficiência é fundamental.

Apesar dos estudos em andamento, verificou-se que ainda há muito a ser feito para a descoberta de maneiras de avaliar e de incentivar um comportamento mais eficiente dos usuários, principalmente através da criação de sistemas mais intuitivos para serem utilizados. Mahdavi e Proglhof (2009), após analisarem a interação de usuários quanto ao uso de cortinas, janelas e luminárias, em escritórios na Áustria, constataram quão difícil é se estimar as variáveis do comportamento de um único indivíduo em uma edificação, sendo necessário fazer uma avaliação de tendências em grupos específicos. Além disso, concluíram que os resultados obtidos em um prédio dificilmente poderão ser utilizados em outro, visto que deve ser levado em conta, entre outros aspectos, o uso de cada edificação, o contexto em que está inserida e o padrão cultural dos usuários. Desse modo, a intenção deste trabalho foi verificar tendências de comportamento relacionadas ao uso dos sistemas de iluminação, ventilação e controle da incidência solar conjugadamente e, através da observação destes comportamentos, identificar as barreiras e as potencialidades dos sistemas e propor melhorias nos mesmos que possam ser generalizadas para outros edifícios.

\section{OBJETIVO}

O objetivo desse estudo é analisar a influência do comportamento dos usuários na eficiência energética de edificações no que diz respeito ao uso do sistema de iluminação, dos sistemas de controle da incidência solar e do sistema de ventilação e verificar de que forma os sistemas e as edificações como estão propostos influenciam no comportamento dos usuários.

\section{MÉTODO}

\subsection{Estudo de Caso: Escola de Arquitetura e Design da UFMG}

Para a presente pesquisa foram investigadas três salas de aula e três salas do Laboratório de Conforto Ambiental e Eficiência Energética no Ambiente Construído (LABCON) da Escola de Arquitetura da UFMG (Figura 1), todas condicionadas naturalmente. As salas possuem aberturas voltadas para as fachadas norte e sul (sala 315), leste (sala 318) e oeste (sala 320A e salas do laboratório). As salas do Laboratório possuem ventilação mecânica associada à ventilação natural, através de ventiladores de teto. Como sistema de controle da incidência solar, a sala 315 possui cortinas do tipo rolôs translúcidas em todas as janelas e brises nas janelas localizadas na fachada norte. A sala 318 possui cortinas blackout e a sala 320A possui, além das cortinas blackout, as folhas de vidro da janela pintadas com tinta branca. As três salas do Laboratório possuem persianas do tipo aletas horizontais metálicas na cor branca. Todas as salas estudadas apresentam controle manual para acionamento da iluminação artificial, localizado internamente à sala, ao lado da porta de acesso à mesma, atendendo ao pré-requisito "Divisão de Circuito" do RTQ-C. 
Figura 1 - Salas 315, 318 e 320A e salas 01, 02 e 03 do LABCON, respectivamente.
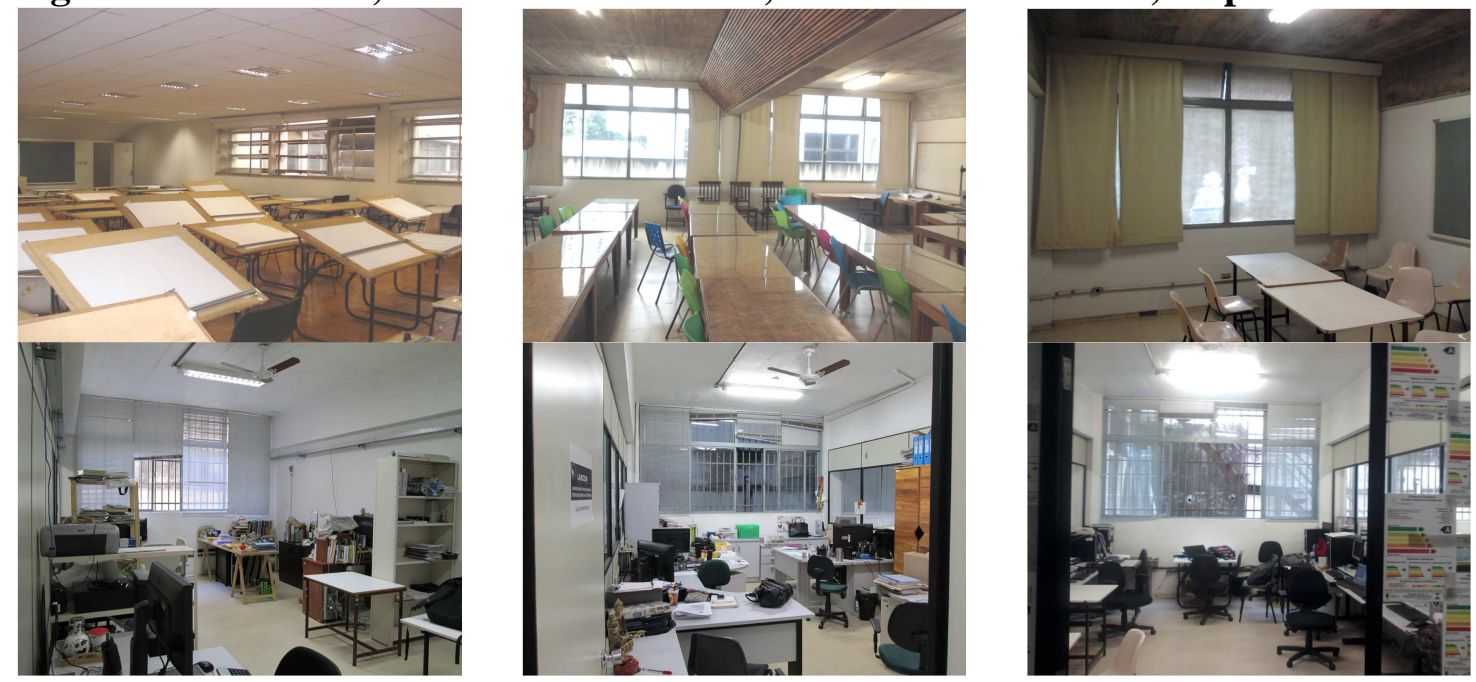

\subsection{Verificação da Iluminação natural e artificial disponível nas salas estudadas}

Para o diagnóstico inicial das salas estudadas neste trabalho foi analisada a autonomia de luz natural das salas, utilizando o software Daysim, e o os horários em que havia incidência de radiação solar direta nas mesmas, utilizando o programa Luz do Sol.

Para verificação da iluminância atual das salas foram feitas medições in loco com o uso de luxímetros digitais (modelo: MLM-1010-Minipa) com o intuito de averiguar o nível de iluminação fornecido pelo sistema de iluminação artificial existente, no que diz respeito ao cumprimento das recomendações da NBR 5413/1992, assim como as possíveis necessidades de adequação do sistema para atender à ISO 8995-1/2013 ${ }^{1}$. A verificação foi feita seguindo a norma NBR 5382/1985 (Verificação de iluminância de interiores). Foram levantados ainda, para os ambientes de estudo de caso, o cumprimento dos pré-requisitos de controle de iluminação do RTQ-C e a densidade de potência instalada, avaliando a classificação dos sistemas de iluminação das salas de acordo com o programa PBE Edifica.

\subsection{Observação in loco}

Para a coleta dos dados de observação, as salas foram observadas durante 86 dias, nos períodos matutino e vespertino. Para a coleta de dados foram preenchidas fichas de observação, contemplando os seis aspectos destacados a seguir:

-“Características Gerais”: horário de uso da sala; incidência de radiação solar direta; e tipo de aula - prática ou teórica (para as salas de aula).

-“Atividades Visuais”: uso de ferramentas de projeção (para as salas de aula).

-“Ocupação”: identificação, em planta, das mesas ocupadas durante a observação.

-“Sistemas de Iluminação": identificação de quando os usuários acendiam e/ou apagavam as luzes, da motivação para fazê-lo e do responsável pela alteração.

-“Sistemas de controle da Incidência Solar”: identificação da forma de atuação nestes.

-"Ventilação Natural": verificação da forma de atuação no sistema de ventilação.

\footnotetext{
${ }^{1}$ A Escola foi projetada anteriormente a essa norma, não sendo esperado, portanto, que ela atendesse aos requisitos da mesma.
} 
A finalidade do diagnóstico realizado para as salas e do preenchimento das fichas de Observação foi, analogamente à técnica da ISO 50.001/2011- Verificação - pontuar as barreiras e potencialidades dos sistemas existentes nas salas estudadas e comparar o comportamento dos usuários de salas de aula com o comportamento dos usuários das salas do Laboratório.

\section{RESULTADOS}

\subsection{Diagnóstico}

Durante o diagnóstico realizado nas salas estudadas, observou-se através de simulação no software Luz do Sol que o brise existente na sala 315 protege significativamente a incidência de radiação solar direta na fachada norte. A fachada sul, por sua vez, recebe radiação solar direta nos meses de verão, em horários próximos ao meio-dia, que pode ser controlada pelos rolôs. No que se refere ao sistema de iluminação artificial, as luminárias estão divididas em cinco circuitos e consideram a contribuição da iluminação natural e o uso do data-show. Verificou-se, através do software Daysim, que as luminárias próximas às janelas poderiam ser mantidas apagadas durante todo o período matutino e durante parte do período vespertino.

Para a sala 318 , verificou-se que, por não permitirem a sobreposição de todos os painéis, as cortinas existentes bloqueiam $40 \%$ da área das janelas quando estão totalmente abertas e que a radiação solar incide diretamente nas carteiras localizadas próximas às janelas no final das manhãs. Em relação ao sistema de iluminação artificial a sala possui seis luminárias divididas em dois circuitos. No entanto, esta divisão não permite o uso integrado da iluminação natural e artificial, ou o desligamento da luminária localizada próxima à parede em que são feitas as projeções separadamente das demais. Através das simulações feitas pelo software Daysim, ao considerar as janelas parcialmente obstruídas pelas cortinas, verificou-se que, caso os circuitos estivessem divididos de modo a permitir apagar as luminárias próximas à janela separadamente das demais, a sala possuiria, próximo às aberturas, $100 \%$ de autonomia de luz durante o período matutino e $80 \%$ durante o período vespertino.

Para a sala 320A, as cortinas totalmente abertas obstruem 50\% da área de janela. Além disso, a tinta branca sobre os vidros também bloqueia a luz natural. A radiação solar incide diretamente nas carteiras no período vespertino. O sistema de iluminação artificial da sala é composto por duas luminárias que fazem parte do mesmo circuito, o que não permite o uso da iluminação natural integrada à artificial. Observou-se, pelo programa Daysim, que com as cortinas e o sistema de iluminação artificial instalados atualmente na sala, não é possível o uso integrado dos sistemas de iluminação natural e artificial. Todavia, considerando-se os vidros sem obstrução (pela tinta ou pela cortina) e as luminárias divididas em dois circuitos, a luminária próxima à janela poderia ser mantida apagada durante $80 \%$ do período matutino, turno em que não há incidência de radiação solar direta nesta sala. Durante o período vespertino, em função da incidência de radiação solar direta, as cortinas tendem a ser mantidas fechadas, o que diminui o potencial de uso da iluminação natural.

Para as salas do Laboratório, as persianas instaladas permitem diferentes níveis de controle da incidência solar, de acordo com a posição das aletas, sem perda completa da iluminação natural disponível. Há radiação solar direta no interior das salas durante o período vespertino. As luminárias encontram-se paralelas às janelas e divididas em mais de um circuito, apresentando grande potencial de uso integrado da iluminação natural e 
artificial. De acordo com os dados simulados através do software Daysim, para o período matutino, as luminárias localizadas próximas à janela possuem potencial para serem mantidas desligadas durante $94 \%$ do tempo. No período vespertino, a autonomia de luz é maior, atingindo $100 \%$ na área de abrangência das luminárias próximas às janelas. Todavia, em função da incidência de radiação solar direta durante este período, a luz natural tende a ser pouco aproveitada, em função da manutenção das persianas fechadas ou parcialmente fechadas, dificultando a entrada de luz natural.

Verificou-se, pela NBR 5282/1985, que todas as salas de aula estudadas atingem os valores mínimos de iluminância recomendados pela NBR 5413/1992 para as mesmas, enquanto nenhuma das salas do Laboratório de Conforto atende a estas recomendações. Nenhuma das salas estudadas atende aos valores médios da norma atual ISO 8995/2013. Desse modo, embora ao analisarmos isoladamente estas salas pelo programa PBE Edifica (Figura 2), elas apresentam boa classificação em função de sua baixa DPI (Densidade de Potência Instalada) e do cumprimento dos pré-requisitos ou de parte deles para os sistemas de iluminação, elas não podem ser consideradas eficientes, visto que não atendem os níveis de iluminância exigidos pela norma atual.

\section{Figura 2 - Análise da classificação dos sistemas de iluminação das salas estudadas pelo programa PBE Edifica}

\begin{tabular}{|c|c|c|c|c|c|c|c|c|c|c|c|c|c|}
\hline \multirow[b]{2}{*}{ Ambiente } & \multirow{2}{*}{$\begin{array}{c}\text { Atividade } \\
\text { Correspondente }\end{array}$} & \multirow[b]{2}{*}{$\begin{array}{l}\text { Área } \\
\text { Total }\end{array}$} & \multicolumn{4}{|c|}{ REFERÊNCIAS PBE EDIFICA } & \multirow{2}{*}{$\begin{array}{l}\text { POTÊNCIA } \\
\text { INSTALADA }\end{array}$} & \multirow[b]{2}{*}{$\begin{array}{c}\text { DPI } \\
\left(\mathrm{W} / \mathrm{m}^{2}\right)\end{array}$} & \multirow[b]{2}{*}{ EqNumDPI } & \multicolumn{2}{|c|}{\begin{tabular}{|l|} 
PRÉ-REQUISITOS \\
\end{tabular}} & \multirow[b]{2}{*}{ EqNumDPI } & \multirow[b]{2}{*}{$\begin{array}{c}\text { Classificação } \\
\text { PBE Edifica }\end{array}$} \\
\hline & & & DPILA & DPIL B & DPILC & DPIL D & & & & $\begin{array}{l}\text { DIVISÃO DE } \\
\text { CIRCUITOS }\end{array}$ & $\begin{array}{c}\text { CONTRIBUIÇÃO DA } \\
\text { LUZ NATURAL }\end{array}$ & & \\
\hline 315 & salas de aula & 154,87 & 10,2 & 12,24 & 14,28 & 16,32 & 1562 & 10,09 & 5 & $\operatorname{sim}$ & sim & 5 & A \\
\hline 318 & salas de aula & 89,65 & 10,2 & 12,24 & 14,28 & 16,32 & 455 & 5,08 & 5 & Sim & não & 3 & C \\
\hline $320 \mathrm{~A}$ & salas de aula & 34,48 & 10,2 & 12,24 & 14,28 & 16,32 & 260 & 7,54 & 5 & Sim & não & 3 & C \\
\hline LABCON SALA 01 & escritórios & 26,13 & 11,9 & 14,28 & 16,66 & 19,04 & 130 & 4,98 & 5 & $\operatorname{sim}$ & $\operatorname{sim}$ & 5 & $\bar{A}$ \\
\hline LABCON SALA 02 & escritórios & 26,13 & 11,9 & 14,28 & 16,66 & 19,04 & 195 & 7,46269 & 5 & Sim & Sim & 5 & $\bar{A}$ \\
\hline LABCON SALA 03 & escritórios & 40,64 & 11,9 & 14,28 & 16,66 & 19,04 & 260 & 6,39764 & 5 & Sim & Sim & 5 & A \\
\hline
\end{tabular}

\subsection{Observações e Análise de Resultados}

Para as salas de aula, observou-se que o uso do sistema de iluminação artificial estava associado ao uso de ferramentas de projeção, em 100\% das aulas observadas em que houve uso do data-show, para a sala 315 , em $28 \%$, para a sala 318 e em $67 \%$, para a sala 320A. Por outro lado, para todas as salas do LABCON verificou-se uma relação direta entre o uso das luminárias e a ocupação da sala em $72 \%$ das observações.

Para as salas 318 e 320A, com circuitos que não permitiam a contribuição da luz natural para os sistemas de iluminação e com cortinas que, mesmo quando totalmente abertas, bloqueavam parte da iluminação natural, não foram verificadas quaisquer relações entre o uso do sistema de iluminação artificial e a disponibilidade de luz natural. No entanto, para a sala 315, em que a divisão das luminárias em circuitos e a existência rolôs translúcidos permitiam a entrada de luz natural na sala, esta foi considerada em $75 \%$ das aulas teóricas observadas. O mesmo ocorreu para as salas do Laboratório em que, embora as luminárias próximas à janela não tenham sido apagadas em função da disponibilidade da luz natural, os usuários as utilizaram de uma forma mais eficiente, ao relacionarem o uso destas à ocupação da sala. Verificou-se, deste modo, que possuir diferentes opções de uso do sistema de iluminação, influencia na sua utilização, ao permitir que os ocupantes utilizem os sistemas da maneira que eles considerem mais adequada, o que confirma os achados de Gyberg e Palm (2009) de que para alterar o comportamento dos usuários deve-se garantir que as escolhas partam do indivíduo, e esá de acordo com as pesquisas de Norman (2010) que afirma que o uso ineficiente dos 
sistemas propostos é consequência de falhas de projeto e não do comportamento dos usuários.

Verificou-se ainda, para as salas de aula, uma hierarquia em relação ao uso do sistema de iluminação, sendo o professor o responsável por $89 \%$ das alterações feitas neste sistema. Por sua vez, para as salas do LABCON, o primeiro usuário a chegar foi o principal responsável pelo status do sistema de iluminação tanto natural quanto artificial nas mesmas. Os usuários que chegaram a seguir nas salas de aula ou nas salas do laboratório tenderam a manter o sistema de iluminação da maneira como ele foi encontrado, alterando o mesmo apenas ao se sentirem incomodados pela falta de iluminação. Verificou-se deste modo que, conforme esperado após os estudos da pesquisa de Fritsch et al (1990), a situação do sistema de iluminação encontrada pelos usuários ao entrarem em uma sala ocupada irá influenciar em seu uso posterior. O que mudou de uma tipologia a outra foram os autores das modificações nos sistemas e o número de atuações sobre os mesmos. Para as salas de aula, a maioria das alterações ocorreu no início e término das aulas, enquanto, para o laboratório, além destas alterações, houve alterações associadas à chegada de novos ocupantes na sala, confirmando a experiência de Reinhart e Voss (2006), acerca das diferenças de comportamento entre grupos de indivíduos e indivíduos isolados. Essas observações reforçaram ainda as conclusões de Lindelof e Morel (2006), de que os usuários tendem a acionar as luminárias ao chegar e sair nos ambientes e neste intervalo atuam nas mesmas apenas ao se sentirem incomodados.

No que diz respeito a dificuldades relacionadas ao uso do sistema de iluminação, verificou-se, para as salas de aula, que quanto maior o número de controles existentes, maior o grau de dificuldade dos usuários com o uso destes. Houve ainda dificuldade em saber se as lâmpadas estavam acesas ou apagadas, o que se deveu ao fato das luminárias serem embutidas, de modo que não se enxerga a lâmpada, mas o brilho da luz nos planos de trabalho. Para as salas do LABCON não foram observadas dificuldades significativas para utilizar o sistema de iluminação artificial. Os usuários destas salas memorizaram o funcionamento dos controles. Um usuário do Laboratório trouxe uma luminária de tarefa, acionada por ele em alguns momentos em que a sala estava sendo observada. Esse comportamento diferenciado para as salas do LABCON, com maior número de atuações no sistema de iluminação, somado à memorização do funcionamento deste e às adaptações feitas no mesmo, permitiu verificar um comportamento típico de "moradores" para os ocupantes destas salas, conforme Hertzberger (2010). Por sua vez, nas salas de aula, observou-se que, de modo geral, os ocupantes se comportam como "usuários", atuando apenas nos sistemas necessários ao bom funcionamento da sala, não tendo sido feitas adaptações durante os períodos de observações em geral.

No que diz respeito ao uso do sistema de ventilação observou-se uma tendência em abrir ou manter as janelas abertas ou parcialmente abertas durante todas as observações para as seis salas, o que foi recorrente em $95 \%$ das observações nas salas de aula e em $87 \%$ dos dias observados nas salas do LABCON. A tendência foi abrir as janelas ao chegar às salas ou mantê-las abertas, permitindo a ventilação natural durante o período em que a sala estava sendo utilizada. Nas salas de aula, os autores das alterações nas janelas variaram em função da sala e do tipo de aula observada: os professores atuaram nas janelas principalmente durante aulas teóricas, enquanto os alunos atuaram nas mesmas, preferencialmente durante atividades práticas, em que estavam sentados próximos às janelas. Para as salas do Laboratório, por sua vez, os principais autores das alterações nas janelas foram os primeiros a chegarem à sala. Para as salas de aula, verificou-se 
ainda um desejo de manter a ventilação cruzada visto que, as portas tenderam a ser mantidas abertas, com intuito de permitir que a sala ficasse mais bem ventilada. No entanto, devido ao ruído do corredor, estas foram fechadas ao longo das aulas em diversas observações. Para as salas do Laboratório, verificou-se ainda que, associado ao uso das janelas os usuários acionaram os ventiladores durante parte dos dias observados, independente de sua completa abertura. Todavia, este comportamento não está relacionado à passividade dos usuários destas salas e sim à dificuldade de uso das janelas - parte delas necessitava de manutenção, exigindo esforço para sua completa abertura. Em uma das salas, as persianas localizadas sobre as folhas móveis eram mantidas fechadas em função do pedido de um usuário da sala e de problemas de manutenção, dificultando a abertura da janela localizada sob a mesma.

No que diz respeito ao uso do sistema de controle da incidência solar, ele ocorreu em $12 \%$ das aulas observadas, sendo $80 \%$ destas alterações feitas por alunos sentados próximos às cortinas alteradas, preferencialmente durante aulas práticas $(75 \%$ das alterações). $80 \%$ destas alterações ocorreram na sala 320A durante o período vespertino. Acredita-se que o elevado número de alterações feitas nas cortinas desta sala deveu-se à incidência de radiação solar direta neste período, somada à preferência dos alunos se sentarem próximos à janela, associada à melhor condição de ventilação, independente da radiação solar direta. Isso se torna claro com o grande número de alterações na posição das cortinas, acompanhando a posição do sol e mantendo a ventilação na sala, simultaneamente. Para as salas do laboratório, por sua vez, verificou-se uma relação entre o uso das persianas e o uso do sistema de ventilação: As persianas foram alteradas em $45 \%$ dos dias observados, sendo $78 \%$ das alterações feitas por usuários sentados próximos às mesmas. Dentre as alterações feitas para abrir as persianas, $94 \%$ foram para alterar as persianas centrais, ou seja, o ato de abrir as persianas estava muito mais relacionado ao uso do sistema de ventilação do que a garantia de melhor disponibilidade de iluminação natural para a sala. No entanto, observou-se para as salas 01 e 02 do laboratório uma intenção em se garantir maior disponibilidade de luz natural, independente do uso das janelas, pois, ao serem analisados os dias em que pelo menos uma das persianas das bordas da janela foi ou já estava aberta para sala 01 , isso ocorreu em $50 \%$ dos dias observados e para a sala 02 , em $35 \%$ dos dias observados. A maior parte das alterações nas persianas no período vespertino ocorreu com intuito de fechar as mesmas, em função de incômodos gerados pela incidência de radiação solar direta na sala. Em seguida, as persianas tenderam a ser abertas novamente. Estes dados reforçam que os usuários tendem a atuar nos sistemas em função da posição dos seus controles e que alterações feitas no sistema são relacionadas a incômodos extremos. Não houve dificuldades de uso das persianas ou cortinas associadas ao não entendimento do funcionamento destas.

Para as salas do Laboratório de Conforto foram observadas algumas particularidades que reforçaram a característica de "moradores" dos ocupantes destas salas: houve maior interação entre os usuários no que diz respeito ao acionamento de sistemas e os usuários tenderam a expressar suas preferências por meio de avisos sobre o uso dos sistemas..

\section{CONCLUSÕES}

A partir do diagnóstico e das observações feitas nas salas estudadas, concluiu-se que as recomendações para o sistema de iluminação, feitas pelo sistema de etiquetagem PBE Edifica para edifícios comerciais, de serviços e públicos contribuem para a melhoria do uso deste sistema, ao permitir diversas opções de uso do mesmo. Por sua vez, o uso de sistemas de controle da incidência solar que permitam a incidência de mais luz natural, 
como brises externos, persianas horizontais ou rolôs translúcidos nas salas também é uma alternativa para incentivar o uso integrado da iluminação natural e artificial e deve ser considerado durante a elaboração de novos projetos. Como, de modo geral, o uso do sistema de persianas e cortinas está mais relacionado ao uso das janelas para ventilação do que à busca por maior disponibilidade de luz natural nas salas, com tendência a atuar-se mais nos sistemas existentes sobre as folhas móveis das janelas, do que naqueles sobre as folhas fixas das mesmas, o uso de persianas que cubram duas folhas da janela (uma fixa e uma móvel), simultaneamente, como incentivo à abertura da persiana sobre a folha fixa da janela deveria ser testado.

Verificou-se que o primeiro usuário a chegar aos ambientes tende a ser o principal responsável por atuar nos sistemas ali existentes. Logo, é importante que este usuário encontre condições adequadas - de iluminação, ventilação e controle da incidência solar - ao entrar neste ambiente. A padronização da lógica de posicionamento dos apagadores ou ainda a relocação dos mesmos de maneira mais intuitiva aos usuários são recomendados.

Por fim, se os usuários tendem a atuar nos sistemas existentes ao chegar e sair dos ambientes ou quando estão incomodados, conclui-se que os melhores projetos são aqueles que menos necessitam ser alterados pelos usuários. Portanto, os projetistas devem estar atentos aos diversos fatores que podem gerar incômodos aos usuários. Conforme afirmado por Gyberg e Palm (2009) a eficiência das edificações depende da concepção arquitetônica por trás do projeto. Verificou-se, por exemplo, que ventilação cruzada é desejável nas salas. Deste modo, a garantia de ventilação sem a necessidade de abertura das portas, o que pode gerar incômodos do ponto de vista acústico, é recomendada. Do ponto de vista da iluminação, a escolha de orientações adequadas para cada uma das fachadas, em função das atividades que serão exercidas é um ponto que deve ser observado, assim como trabalhar elementos externos - como brises, prateleiras de luz, ou outros tipos de proteções - que garantam o conforto dos ambientes sem necessitar do uso de elementos de proteção interna, que demandem esforço dos usuários para alterá-los. A sala 315 é um bom exemplo disto: a sala possui aberturas orientadas nas fachadas norte e sul, garantindo a ventilação cruzada sem que seja necessário manter a porta aberta. A fachada sul permite boa iluminação natural, sem incidência de radiação solar direta e a fachada norte, embora receba radiação solar durante alguns períodos do ano, foi protegida por um brise, que controla esta radiação. Com isso, embora existam rolôs na sala, eles são pouco utilizados. Assim, o usuário tem a possibilidade de utilizar o sistema, mas não precisa utilizá-lo, pois não se sente incomodado pelo excesso de radiação solar. Desse modo, conclui-se que os sistemas propostos influenciam o comportamento dos usuários e, por isso, devem permitir um uso eficiente.

Compreender o usuário não é uma tarefa fácil, principalmente porque não existe um comportamento humano-tipo, e sim tendências de comportamento, que são alteradas a todo instante, o que dificulta padronizações. Isso significa que a tarefa de entendê-los deve ser feita a cada novo projeto e em um ciclo de melhoria contínua, a partir de verificações, porque os projetos não são estáticos: as necessidades mudam, assim como os usuários de cada um dos espaços. As decisões tomadas devem contemplar a qualidade dos ambientes alterados e, principalmente o bem-estar dos usuários destes ambientes, que não devem simplesmente ser forçados a se adaptar à arquitetura que lhes é entregue. As alterações feitas em projetos antigos, assim como os novos projetos, devem seguir os atuais conceitos acerca do papel do usuário na arquitetura, que classificam os usuários como detentores de um papel efetivo na arquitetura. Por fim, 
conclui-se que é apenas observando o usuário que se consegue entendê-lo e é apenas após entendê-lo que se consegue fazer bons projetos.

\section{AGRADECIMENTOS}

À CAPES, pelo apoio recebido através de bolsa de pesquisa de mestrado. À FAPEMIG e ao Centro Universitário de Formiga (UNIFOR-MG) pelo apoio financeiro para participação neste Encontro Nacional de Tecnologia do Ambiente Construído.

\section{REFERÊNCIAS}

ASSOCIAÇÃO BRASILEIRA DE NORMAS TÉCNICAS: NBR ISO 50.001: Sistemas de Gestão de Energia: Requisitos com orientação para uso. Rio de Janeiro, 2011.

ASSOCIAÇÃO BRASILEIRA DE NORMAS TÉCNICAS: NBR 5382: Verificação de Iluminância de Interiores. Associação Brasileira de Normas Técnicas. Rio de Janeiro, 1985.

ASSOCIAÇÃO BRASILEIRA DE NORMAS TÉCNICAS: NBR 5413: Iluminância de interiores. Associação Brasileira de Normas Técnicas. Rio de Janeiro, 1992.

ASSOCIAÇÃO BRASILEIRA DE NORMAS TÉCNICAS: NBR ISO/CIE 8995-1: Iluminação de ambientes de trabalho. Rio de Janeiro, 2013.

CRISP, V.H.C. The light switch in buildings. Lighting Research and Technology. 1978. Vol.10, no.2, p. 69-82.

FRITSCH, R.; KOHLER, A.; NYGARD-FERGUSON, M.; SCARTEZZINI, J.L. A stochastic model of user behaviour regarding ventilation. In: Building and Environment, 25 (2), 1990, p. $173-181$.

GYBERG, P.; PALM, J. Influencing households' energy behaviour - how is this done and on what premises? 2009. Energy Policy, vol. 37, no. 7, p. 2807-2813.

HERTZBERGER, H. Lições de Arquitetura. São Paulo: Martins Fontes, 2010.

LINDELOF, D.; MOREL, N. A field investigation of the intermediate light switching by users. Energy and Buildings. 2006 Jul: 1-29.

LINO, Sulamita Fonseca, VILLELA, Clarisse Martins, FIGUEIREDO, Cesar Augusto. Arquitetura sem "modo de usar", 2009. Disponível em: $<$ http://cumincades.scix.net/data/works/art/sigradi2009 955.content.pdf $>$. Acesso em 02 nov. 2012.

MAHDAVI A, PROGLHOF, C. User Behavior and energy performance in buildings. IEWT. 2009: 1-13. Disponível em:

$<$ http://eeg.tuwien.ac.at/eeg.tuwien.ac.at_pages/events/iewt/iewt2009/papers/4E_1_MAHDAVI _A_P.pdf $>$. Acesso em: 09 out. 2011

REINHART, C.F. Daysim in Sketch Up - su2ds.manual.pdf. 2013. Disponível em: $<$ daysim.ning.com/Page/daysim-in-sketchup>. Acesso em: 06 dez. 2013. 